\title{
A Multicenter Retrospective Analysis on Clinical Effectiveness and Economic Assessment of Compound Reserpine and Hydrochlorothiazide Tablets (CRH) for Hypertension
}

This article was published in the following Dove Press journal:

ClinicoEconomics and Outcomes Research

\author{
Shunping $\mathrm{Li}^{1,2}$ \\ Xiaohan Liu ${ }^{1,2}$ \\ Lanting $\mathrm{Li}^{3}$
}

'School of Health Care Management, Shandong University, Jinan 2500I2, People's Republic of China; ${ }^{2} \mathrm{NHC}$ Key Laboratory of Health Economics and Policy Research, Shandong University, Jinan 2500 I2, People's Republic of China;

${ }^{3}$ Shanghai Palan DataRx Co., Ltd., Shanghai, People's Republic of China
Correspondence: Shunping Li Email lishunping@sdu.edu.cn
Background/Objective: As the first generation of anti-hypertensive drug independently developed by China, Compound Reserpine and Hydrochlorothiazide Tablet (CRH) has been widely used in China for more than 40 years. However, limited studies are available for the performance of $\mathrm{CRH}$ for the treatment of hypertension in real-world setting in China. This study aimed to evaluate the comparative clinical effectiveness and treatment costs between $\mathrm{CRH}$ and three other anti-hypertensive agents that include, Triprolidine Hydrochloride (TH: Diovan), Amlodipine Besylate Tablet (ABT: Norvasc), and Nifedipine Tablets (NT: Procardin) in real-world clinical practice.

Methods: This was a multicentre, retrospective study conducted from May 2011 to May 2016 at four tertiary hospitals in China. Data from patients' electronic medical records (EMR) were retrieved and analysed. A retrospective propensity score-matched analysis was used for three pairs of comparisons. Systolic blood pressure (SBP), diastolic blood pressure (DBP), and overall blood pressure (BP) control rate on the 10th and 20th days after treatment were compared. The overall cost of treatment was analysed across groups.

Results: In three pairs of comparison, the patients who received CRH treatment obtained better blood pressure control at both day 10 and day 20. In addition, the patients who received $\mathrm{CRH}$ had lower total treatment costs compared with the other three antihypertensive drugs. Influential factor analysis showed that CRH is associated with a higher probability of BP control compared with the other three monotherapies in real-world clinical practice.

Conclusion: The patients received CRH showed a higher overall BP control rate than the other three commonly prescribed anti-hypertensive drugs, which indicates that $\mathrm{CRH}$ has a better benefit in BP control for hypertensive patients. Also, the total cost for hypertension treatment is lower in CRH patients compared with the other three comparator drugs. These findings suggest that $\mathrm{CRH}$ could be an effective and cost-effective option for hypertensive patients.

Keywords: hypertension, compound reserpine and hydrochlorothiazide, clinical effectiveness, economic analysis

\section{Introduction}

Elevated blood pressure is the biggest single contributor to the global burden of disease and to global mortality, ${ }^{1,2}$ especially in China. ${ }^{3}$ This situation is expected to worsen in the coming decades as the global population increases and ages. ${ }^{4}$ The proportions of awareness, treatment, and control of hypertension were much lower 
in low- and middle-income countries than in high-income countries, especially in China, ${ }^{5,6}$ have barely been improved over the years. ${ }^{6,7}$ China PEACE Million Persons Project reported that $44.7 \%$ of the Chinese population are affected by hypertension, and of those affected, $30.1 \%$ received treatment and only $7.2 \%$ had achieved control. $^{8}$

Hypertension is one of the major risk factors of cardiovascular diseases (CVD) and one of the leading causes of global mortality. ${ }^{9}$ About half of the deaths from CVD were related to hypertension in $2008 .{ }^{10}$ Hypertension may affect more than $90 \%$ of hypertensive individuals during their lifetime, ${ }^{11}$ and morbidity related to hypertension lead to enormous economic burden to patients and societies. $^{12,13}$ Therefore, controlling reduction of blood pressure within the healthy range is one of the major challenges for preventing complications and the future burden of CVD. ${ }^{14}$

Despite the availability of effective antihypertensive agents, hypertension remains poorly controlled in the majority of patients. ${ }^{15}$ Therefore, combination therapy is always recommended in guidelines for hypertension, which can improve patient adherence, compliance, and persistence. ${ }^{16}$ Compound Reserpine and Hydrochlorothiazide Tablets $(\mathrm{CRH})$ is a combination drug used for the treatment of hypertension that was independently developed in China. It has been recommended in several guidelines for hypertension treatment. ${ }^{17-19} \mathrm{CRH}$ was invented in the 1970 s by Professor Yingkai Wu, a pioneering cardiothoracic surgeon, and Professor Luogeng Hua who is a famous epidemiologist and mathematician.

To optimize the use of limited health-care resources and to better meet future demands for health services, it is critical to understand the economic impact of hypertension and its associated therapies. ${ }^{13}$ The efficacy of CRH tablet has been demonstrated for many years, ${ }^{20}$ however, limited studies have been conducted to investigate the clinical effectiveness and cost in a real-world setting. The purpose of this study is to compare the clinical effectiveness and cost of $\mathrm{CRH}$ with the other three anti-hypertensive drugs commonly prescribed in clinical practice, namely Triprolidine Hydrochloride (TH: Diovan), Amlodipine Besylate Tablet (ABT: Norvasc) and Nifedipine Tablets (NT: Procardin). This will provide evidence to support rational choice of medicine, optimization of resources allocation and alleviation of economics burden for hypertension patients.

\section{Methods}

\section{Study Population}

This is a multicenter, retrospective study conducted at four tertiary hospitals in China. Data from patients' electronic medical records (EMR) between May 2011 to May 2016 were retrieved. The patient data confidentiality was guaranteed and all study data were de-identified and fully compliant with the Health Insurance Portability and Accountability Act (HIPAA). Therefore, approval from an institutional review board and written informed consent for their data were not required. This study was carried out in accordance with the principles of the Declaration of Helsinki.

The patients who have been diagnosed with hypertension and have taken at least one antihypertensive agent were initially eligible in our analysis. International Classification of Diseases (ICD-10) was used to identify hypertensive patients (I10 - I15). Those who completed at least systolic blood pressure (SBP) or diastolic blood pressure (DBP) measurements once at Day 10 and Day 20 during the treatment were included. The inclusion criteria also included DBP $\geq 40 \mathrm{mmHg}$ and $<150 \mathrm{mmHg}$ and $\mathrm{SBP} \geq 70 \mathrm{mmHg}$ and $<260 \mathrm{mmHg}$. Whereas the patients who have been administrated $\mathrm{CRH}$ and other drugs during the same visit were excluded from analysis. In addition, patients with white coat hypertension or masked hypertension were not included in the analysis.

More than 20,000 patients with essential hypertension diagnosis were eligible and included in the study. Propensity score matching (PSM) analysis was used to reduce the bias due to potential confounding factors in this observational study. The covariates matched for three pairs of comparison include age, sex, disease severity, and medical insurance. For the matched groups, pairs of patients have been matched for comparisons separately. The details of screening flow are provided in Figure 1.

\section{Effectiveness Outcomes and Cost}

\section{Assessment}

Primary clinical effectiveness endpoints were the measurements of DBP, SBP, and overall BP control rate at Day 10 and Day 20 of the treatment. The overall control rate is calculated according to the Guidelines for Prevention and Treatment of Hypertension in China, which is SBP $<140$ and DBP $<90 \mathrm{mmHg}$ at the same time. ${ }^{18,19}$

The direct medical costs related to the treatment were estimated with data collected from the hospital information 


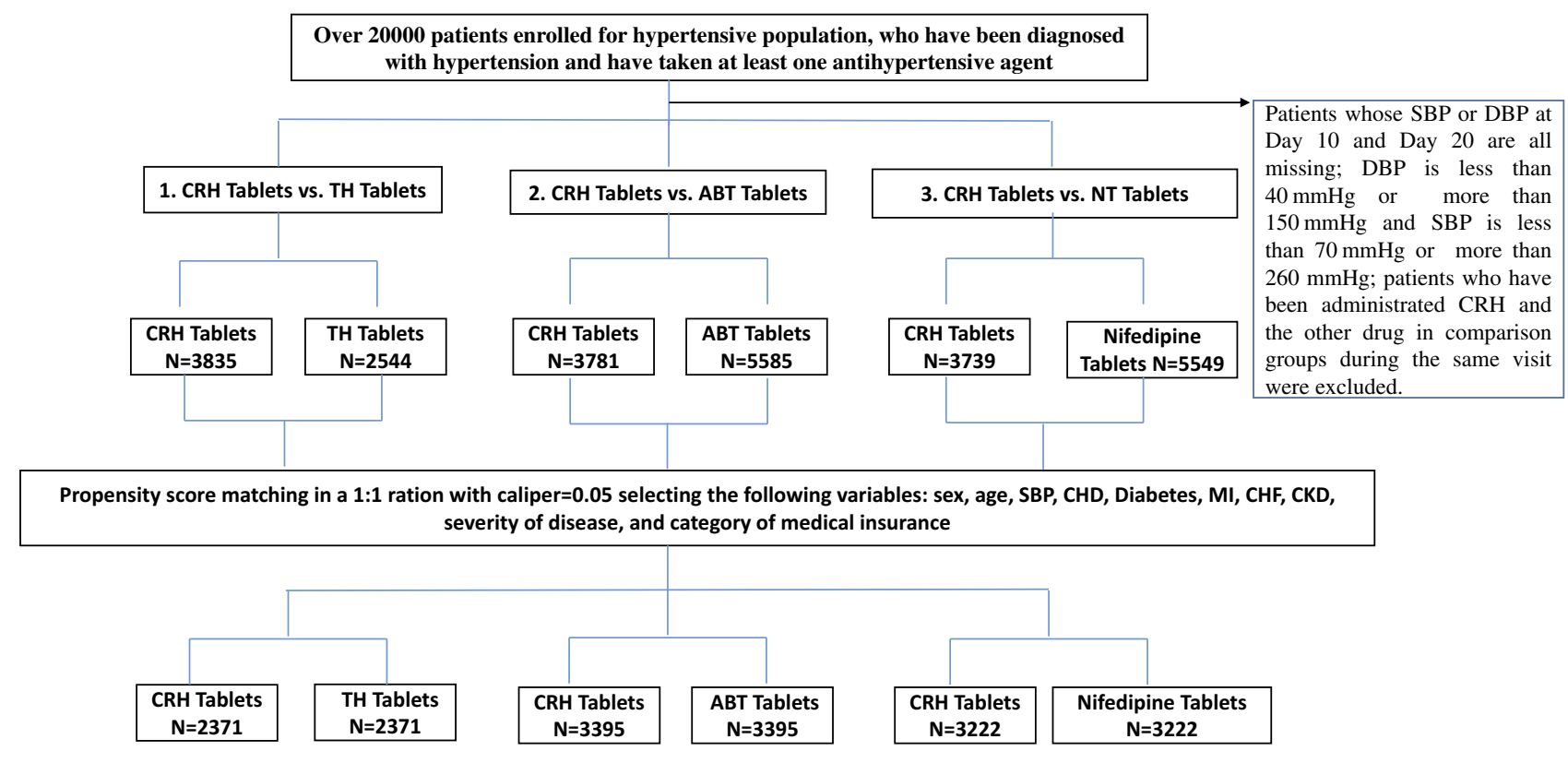

Figure I Screen flow for general hypertensive population.

Abbreviations: CRH Tablets, Compound Reserpine and Hydrochlorothiazide Tablets; TH Tablets, Triprolidine Hydrochloride (Diovan); ABT Tablets, Amlodipine Besylate Tablet (Norvasc); NT, Nifedipine Tablets (Procardin).

system (HIS) and included cost of western medicine and Chinese traditional patent medicine. Costs of treatment were compared between $\mathrm{CRH}$ and comparators in this study.

\section{Statistical Analyses}

PSM was used to adjust significant differences in patient characteristics across treatment groups and reduce the influence of possible confounding factors. To estimate the propensity score, a logistic regression model was used with the covariate variables including (age, sex, disease severity (defined as the baseline hypertension grade for the patients), and categories of medical insurance). After estimating propensity scores, one-to-one nearest-neighbour matching without replacement was performed with a calliper of width equal to 0.05 . The difference of potential confounding variables with $p$-value of $<0.05$ was statistically significant for each test before and after PSM.

For other statistical methods included in this study, continuous variables are presented as minimum, maximum, mean, $\mathrm{SD}$, median and interquartile range (IQR). Categorical variables are expressed as percentage. For the comparison test, two-tailed Student's $t$-test was used for the continuous variables and Fisher's exact test or chisquare test was used for the categorical variables whenever is appropriate. For the comparison test among three different time points, one-way repeated measures ANOVA was used for SBP and DBP comparison. All tests were twosided, with statistical significance at $p<0.05$. In addition, multiple linear regression was used to analyse the influence factors for blood pressure control.

Analyses were conducted with the $\mathrm{R}$ statistical package v.2.13.1 (R Foundation for Statistical Computing, Vienna, Austria).

\section{Results}

\section{Patient Characteristics}

After PSM, a total of 4742 patients were enrolled in CRHTH comparison, 6790 patients in CRH-ABT comparison, and 6444 patients in CRH-NT comparison. Patients' demographics and characteristics for three comparisons are summarized in Table 1.

\section{Effectiveness Outcome}

Results of the primary endpoints including SBP, DBP, and overall BP control rate at day 10 and day 20 were assessed, and results are presented in Table 2. In the 10th days after treatment, the patients in $\mathrm{CRH}$ group showed lower DBP in all three comparison groups (CRH-TH: $75.40 \mathrm{mmHg}$ vs $76.11 \mathrm{mmHg}$; CRH-ABT: $74.99 \mathrm{mmHg}$ vs $75.11 \mathrm{mmHg}$; CRH-NT: $74.21 \mathrm{mmHg}$ vs $76.09 \mathrm{mmHg}$ ). However, at 20 
Table I Patient Characteristics for Three Groups After PSM

\begin{tabular}{|c|c|c|c|c|c|c|}
\hline \multirow[t]{2}{*}{ Demographics } & CRH & TH & CRH & ABT & CRH & NT \\
\hline & \multicolumn{2}{|l|}{$(\mathrm{N}=237 \mathrm{I})$} & \multicolumn{2}{|l|}{$(\mathrm{N}=3395)$} & \multicolumn{2}{|l|}{$(\mathrm{N}=3222)$} \\
\hline Age (years) (mean $\pm S D)$ & $63.73 \pm 12.85$ & $64.14 \pm 12.17$ & $62.35 \pm 12.84$ & $62.59 \pm 12.14$ & $61.92 \pm 13.07$ & $62.07 \pm 12.81$ \\
\hline $\begin{array}{l}\text { Gender (Yes,\%) } \\
\quad \text { Female } \\
\text { Male }\end{array}$ & $\begin{array}{l}1269(53.5) \\
1102(46.5)\end{array}$ & $\begin{array}{l}1265(53.4) \\
1106(46.6)\end{array}$ & $\begin{array}{l}\text { I850 (54.5) } \\
\text { I545 (45.5) }\end{array}$ & $\begin{array}{l}\text { I86I (54.8) } \\
\text { I534 (45.2) }\end{array}$ & $\begin{array}{l}\text { I846 (57.3) } \\
\text { I } 376(42.7)\end{array}$ & $\begin{array}{l}\text { I } 774(55.1) \\
\text { I } 448(44.9)\end{array}$ \\
\hline $\begin{array}{l}\text { Comorbidity (Yes, \%) } \\
\text { CAD } \\
\text { DM } \\
\text { MI } \\
\text { HF } \\
\text { CKD }\end{array}$ & $\begin{array}{l}1803(76.0) \\
1562(65.9) \\
99(4.2) \\
116(4.9) \\
705(29.7)\end{array}$ & $\begin{array}{l}1789(75.5) \\
1539(64.9) \\
88(3.7) \\
90(3.8) \\
696(29.4)\end{array}$ & $\begin{array}{l}2637(77.7) \\
2153(63.4) \\
126(3.7) \\
116(3.4) \\
924(27.2)\end{array}$ & $\begin{array}{l}2645(77.9) \\
2139(63.0) \\
127(3.7) \\
98(0.03) \\
916(27.0)\end{array}$ & $\begin{array}{l}2477(76.9) \\
2076(64.4) \\
104(3.2) \\
102(3.2) \\
854(26.5)\end{array}$ & $\begin{array}{l}2512(78.0) \\
2001(62.1) \\
107(3.3) \\
108(3.4) \\
857(26.6)\end{array}$ \\
\hline $\begin{array}{l}\text { Severity (Yes, \%) } \\
\text { Grade I hypertension } \\
\text { Grade } 2 \text { hypertension } \\
\text { Grade } 3 \text { hypertension }\end{array}$ & $\begin{array}{l}196(8.3) \\
1006(42.4) \\
1148(48.4)\end{array}$ & $\begin{array}{l}170(7.2) \\
985(41.5) \\
1139(48.0)\end{array}$ & $\begin{array}{l}283(8.3) \\
1628(48.0) \\
1597(47.0)\end{array}$ & $\begin{array}{l}247(7.3) \\
1577(46.5) \\
1592(46.9)\end{array}$ & $\begin{array}{l}268(8.3) \\
1484(46.1) \\
153 \mid(47.5)\end{array}$ & $\begin{array}{l}196(6.1) \\
145 \mid(45.0) \\
1453(45.1)\end{array}$ \\
\hline $\begin{array}{l}\text { MI(Yes, \%) } \\
\text { Self-pay } \\
\text { MI covered }\end{array}$ & $\begin{array}{l}32(1.3) \\
2339(98.7)\end{array}$ & $\begin{array}{l}36(1.5) \\
2335(98.5)\end{array}$ & $\begin{array}{l}54(1.6) \\
334 \mid(98.4)\end{array}$ & $\begin{array}{l}56(1.6) \\
3339(98.4)\end{array}$ & $\begin{array}{l}55(1.7) \\
3167(98.3)\end{array}$ & $\begin{array}{l}50(1.6) \\
3172(98.4)\end{array}$ \\
\hline
\end{tabular}

Abbreviations: CAD, coronary artery disease; DM, diabetes mellitus; MI, myocardial infarction; HF, Heart failure; CKD, chronic kidney disease; DBP, diastolic blood pressure; SBP, systolic blood pressure; MI, medical insurance; PSM, propensity score matching.

Table 2 DBP and SBP Assessments for Three Comparisons at Day 10 and Day 20

\begin{tabular}{|c|c|c|c|c|c|c|c|}
\hline \multirow{2}{*}{$\begin{array}{l}\text { Blood Pressure } \\
\text { DBP }\end{array}$} & \multirow{2}{*}{$\begin{array}{l}\text { Time } \\
0 \text { day }\end{array}$} & \multicolumn{2}{|c|}{ CRH-TH $(\mathrm{N}=237 \mathrm{I})$} & \multicolumn{2}{|c|}{ CRH-ABT $(\mathrm{N}=3395)$} & \multicolumn{2}{|c|}{ CRH-NT $(\mathrm{N}=3222)$} \\
\hline & & 76.77 & 81.14 & 76.13 & 80.85 & 71.39 & 83.09 \\
\hline & 10 days & 75.40 & 76.11 & 74.99 & 75.11 & 74.21 & 76.09 \\
\hline & 20 days & 74.85 & 74.32 & 74.52 & 74.45 & 74.28 & 76.33 \\
\hline & $P$ value & \multicolumn{2}{|l|}{0.112} & \multicolumn{2}{|l|}{0.122} & \multicolumn{2}{|l|}{0.028} \\
\hline \multirow[t]{4}{*}{ SBP } & 0 day & 136.59 & 145.60 & 134.12 & 145.13 & 134.62 & $|54.4|$ \\
\hline & 10 days & 131.36 & $|35.2|$ & 130.10 & 135.06 & 129.07 & |39.3| \\
\hline & 20 days & 131.88 & 133.62 & 131.77 & 133.93 & 129.32 & 138.69 \\
\hline & $P$ value & \multicolumn{2}{|l|}{0.196} & \multicolumn{2}{|l|}{0.073} & \multicolumn{2}{|l|}{$<0.001$} \\
\hline
\end{tabular}

Note: $P$ value: One-way repeated measures ANOVA.

Abbreviations: DBP, diastolic blood pressure; SBP, systolic blood pressure.

days of treatment, the patients in $\mathrm{CRH}$ group showed higher DBP in CRH-TH and CRH-ABT comparisons (CRH-TH: $74.85 \mathrm{mmHg}$ vs $74.32 \mathrm{mmHg}$; CRH-ABT: $74.52 \mathrm{mmHg}$ vs $74.45 \mathrm{mmHg}$ ), but lower DBP in CRH-NT comparison (CRH-NT: $74.28 \mathrm{mmHg}$ vs $76.33 \mathrm{mmHg}$ ). In addition, considering the time influence, the patients in $\mathrm{CRH}$ group obtained significantly lower DBP comparing with NT group. But there is no statistical significance achieved in
CRH-TH and CRH-ABT comparisons. For the SBP assessment, the patients in the $\mathrm{CRH}$ group showed a greater decrease compared with the other three drugs. Moreover, the statistical significance was achieved in NT group.

Table 3 shows that $\mathrm{CRH}$ had a higher control rate compared with the other three comparators at day 10 and day 20. In addition, the statistical significance between CRH and NT were achieved for both day 10 and day 20. 
Table 3 BP Control Rate for Three Comparisons at Day 10 and Day 20 (\%)

\begin{tabular}{|l|l|l|l|l|l|l|}
\hline & \multicolumn{2}{|l|}{$\begin{array}{l}\text { CRH-TH } \\
\text { (N=237) }\end{array}$} & \multicolumn{2}{l|}{$\begin{array}{l}\text { CRH-ABT } \\
(\mathbf{N}=3395)\end{array}$} & \multicolumn{2}{l|}{$\begin{array}{l}\text { CRH-NT } \\
\text { (N=322) }\end{array}$} \\
\hline Control rate in 10 days & $62 \%$ & $46 \% *$ & $66 \%$ & $52 \% *$ & $65 \%$ & $45 \% *$ \\
Control rate in 20 days & $66 \%$ & $58 \%$ & $64 \%$ & $57 \%$ & $74 \%$ & $54 \% *$ \\
\hline
\end{tabular}

Notes: $P$ value: Chi-square test. $* P<0.05$.

Abbreviation: BP, blood pressure.

\section{Cost Analysis}

The direct medical cost per patient is shown in Table 4. Figure 2 shows that the $\mathrm{CRH}$ group saved total cost and western medicine cost in all three pairs of comparison. While the cost for Chinese traditional patent medicine for CRH group are higher than the ABT and NT groups separately.

\section{Risk Factors Analysis}

A logistic regression analysis model was used to evaluate the potential risk factors for BP control in this study, and the results are presented in Table 5. In CRH-TH

Table 4 Direct Medical Cost per Patient for CRH Group

\begin{tabular}{|l|l|l|l|}
\hline Cost (¥) & $\begin{array}{l}\text { CRH(-TH) } \\
\text { (Median, IQR) }\end{array}$ & $\begin{array}{l}\text { CRH(-ABT) } \\
\text { (Median, IQR) }\end{array}$ & $\begin{array}{l}\text { CRH(-NT) } \\
\text { (Median, IQR) }\end{array}$ \\
\hline Total cost & $682.9(7 I 2)$ & $664(697.5)$ & $659.3(693.7)$ \\
Western medicine & $449.4(588.6)$ & $518.5(620.3)$ & $433.7(577.9)$ \\
Chinese traditional & $54.2(270.3)$ & $26.6(220.4)$ & $49.2(251.9)$ \\
patent medicine & & & \\
\hline
\end{tabular}

comparison group, younger age and receiving CRH treatment are the protective factors for the control of hypertension. In CRH-ABT comparison group, younger age, female, lower hypertension grade, receiving $\mathrm{CRH}$ treatment, and BMI between 18.5 and 23.9 is found to be protective factors. In CRH-NT comparison group, younger age, grade II hypertension, $\mathrm{CRH}$ treatment received and BMI $<18.5$ are the protective factors.

\section{Discussion}

This study is one of the first few studies that investigated the clinical effectiveness and cost of CRH treatment in the realworld setting in China. To our best knowledge, it is also the first study to assess the comparative clinical effectiveness between $\mathrm{CRH}$ and the other three imported drugs and the results confirmed efficacy in real-world clinical practice. The principal findings of the present study include the followings: first, the CRH treated patients had better blood pressure control at both day 10 and day 20 of treatment. Secondly, CRH treatment was associated with lowers direct medical cost compared with the other three antihypertensive drugs. Thirdly, the regression analysis showed that $\mathrm{CRH}$ has a significantly higher probability to achieve BP control.

For hypertensive patients, reducing blood pressure is the main target in clinical practice. Even $1 \mathrm{mmHg}$ BP decrease would have protective effect from the target organ damage. The assessment criteria of an anti-hypertensive drug include effective BP control, steady BP variability, fewer side effects, escape the organ damage (e.g. kidney, heart, blood

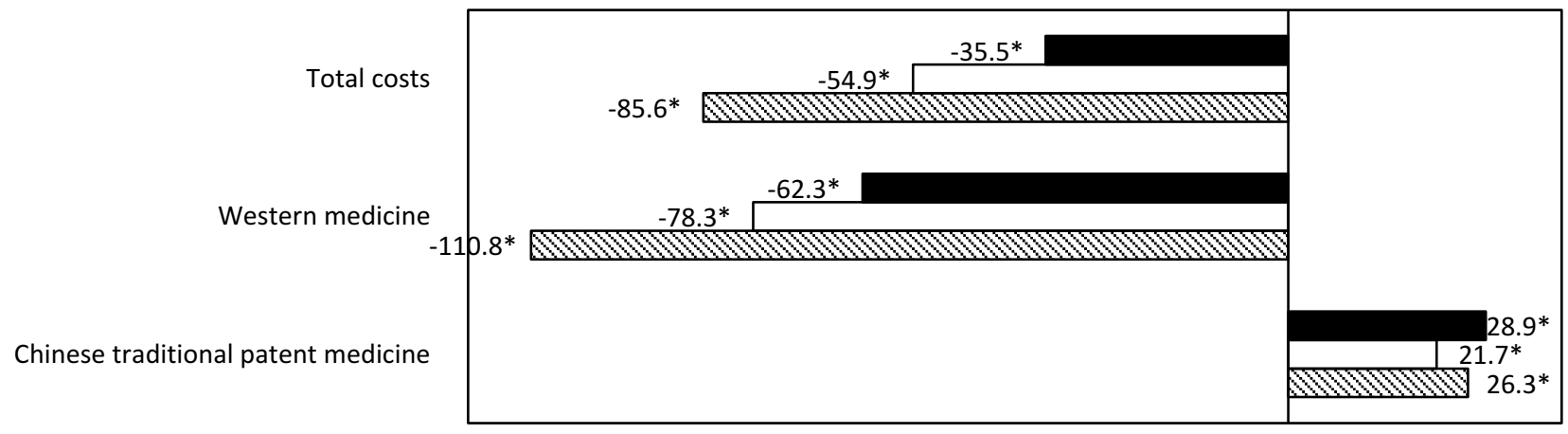

*: $\mathrm{P}$ value is less than 0.05 .

- TH (Triprolidine Hydrochloride(Diovan)); n:ABT(Amlodipine Besylate Tablet(Norvasc)); (Procardin))

Figure 2 Cost-benefit between CRH and the other three comparators. TH (Triprolidine Hydrochloride [Diovan]) is shown with black bar, ABT (Amlodipine Besylate Tablet [Norvasc]) is shown with white bar and NT (Nifedipine Tablets [Procardin]) is shown with shadow bar.

Note: $* \mathrm{P}<0.05$. 
Table 5 Risk Factors Analysis for BP Control Rate

\begin{tabular}{|c|c|c|c|}
\hline \multirow[t]{2}{*}{ Factors } & CRH-TH & CRH-ABT & CRH-NT \\
\hline & OR(95\% Cl) & OR(95\% Cl) & OR(95\% Cl) \\
\hline Constant & $1.64(0.21,9.64)$ & $3.36(1.22,9.54)^{*}$ & $3(1.06,8.81)^{*}$ \\
\hline \multicolumn{4}{|l|}{ Age (Ref. <50) } \\
\hline $50 \sim 64$ & $0.57(0.32,0.96)^{*}$ & $0.61(0.4,0.92)^{*}$ & $0.68(0.45, I)$ \\
\hline $65 \sim 79$ & $0.45(0.26,0.76)^{*}$ & $0.56(0.37,0.83)^{*}$ & $0.56(0.38,0.82)^{*}$ \\
\hline $80 \sim$ & $0.34(0.17,0.66)^{*}$ & $0.42(0.26,0.69)^{*}$ & $0.66(0.4,1.07)$ \\
\hline \multicolumn{4}{|c|}{ Gender (Ref. Female) } \\
\hline Male & $0.83(0.65,1.06)$ & $0.81(0.66,0.98)^{*}$ & $0.84(0.69,1.03)$ \\
\hline \multicolumn{4}{|c|}{ Treatment Duration (Ref. I0 Days) } \\
\hline II 20 days & $5.42(0.37,165.09)$ & $0.71(0.2,2.44)$ & $0.65(0.18,2.27)$ \\
\hline 2130 days & $1.74(0.2,18.9)$ & $0.71(0.16,3.07)$ & $0.39(0.09,1.52)$ \\
\hline$>30$ days & $2.18(0.42,15.97)$ & $1.12(0.44,2.79)$ & $0.72(0.27,1.83)$ \\
\hline \multicolumn{4}{|c|}{ MI (Ref. Without MI) } \\
\hline Ml covered & $1.24(0.8,1.91)$ & $1.13(0.81,1.57)$ & $1.17(0.83,1.65)$ \\
\hline \multicolumn{4}{|c|}{ Hypertension Grade (Ref. IGrade) } \\
\hline II Grade & $1.21(0.93,1.57)$ & $1.23(0.99,1.53)$ & $1.56(1.24,1.96)^{*}$ \\
\hline III Grade & $0.77(0.59,1.01)$ & $0.79(0.63,0.97)^{*}$ & $0.82(0.66,1.02)$ \\
\hline \multicolumn{4}{|c|}{ Treatment (Ref. CRH) } \\
\hline Control drug & $0.72(0.56,0.93)^{*}$ & $0.74(0.59,0.93)^{*}$ & $0.64(0.5 \mathrm{I}, 0.8 \mathrm{I})^{*}$ \\
\hline \multicolumn{4}{|c|}{ Chronic Kidney Diagnosis Before (Ref. No) } \\
\hline Yes & $\mathrm{I} .47(0.83,2.7 \mathrm{I})$ & $1.64(0.94,3)$ & $1.39(0.8,2.52)$ \\
\hline \multicolumn{4}{|c|}{ BMI (Ref. Normal(I8.5-23.9)) } \\
\hline$<18.5$ & $1.65(0.82,3.5)$ & $1.58(0.88,2.95)$ & $1.87(1.04,3.48)^{*}$ \\
\hline $\operatorname{BMI}(24 \sim 27.9)$ & $0.9(0.67,1.19)$ & $0.7(0.56,0.88)^{*}$ & $1.05(0.83,1.32)$ \\
\hline $\mathrm{BMI}(\geq 28)$ & $0.77(0.55,1.08)$ & $0.7(0.53,0.92)^{*}$ & $1.03(0.77,1.37)$ \\
\hline
\end{tabular}

Note: $* P<0.05$.

vessel, and brain), quality of life improvement, lower risk of cardiovascular events, appropriate price, and good treatment adherence. The findings from this study indicated that $\mathrm{CRH}$ exhibited better clinical effectiveness in a real-world setting in comparison with three other anti-hypertensive drugs which are commonly prescribed in clinical practice. Furthermore, the economic assessment results showed that $\mathrm{CRH}$ could result in a lower cost of anti-hypertensive treatment with over, 100 $\mathrm{RMB}$ cost saving in the CRH group compared with the other three imported anti-hypertensive drugs. Similar findings have been reported previously. In a clinical trial that included hypertensive patients from 13 hospitals in 10 regions, it was reported that comparing with indapamide, $\mathrm{CRH}$ showed better outcomes in the control rate for SBP, DBP or SBP and DBP. ${ }^{21}$ A cost-effectiveness study showed that there was no difference for the BP control between CRH and another common antihypertensive treatment, but the expenses for $\mathrm{CRH}$ were only
$40 \%$ of the cost of common anti-hypertensive drugs. The result demonstrated that $\mathrm{CRH}$ is an effective and costeffective treatment option for hypertension. ${ }^{22}$

$\mathrm{CRH}$ displayed its usefulness as a combination therapy. It has been reported that combination drug can reduce BP to a greater extent and achieve BP control more quickly. In addition, the combination may be associated with lower degrees of therapy discontinuation, thus facilitating the achievement of adequate BP control. ${ }^{16} \mathrm{CRH}$ was developed as a combination agent that consists of basic anti-hypertensive drugs and diuretic. The basic antihypertensive drugs include Reserpine and dihydralazine sulfate, and diuretic include hydrochlorothiazide and triamterene.

There are some limitations in our study. Firstly, we only compared the clinical effectiveness at day 10 and day 20 . The data from the real-world setting impose the limitation on this study and the analyses were based on a short-term study 
design. It would be useful to obtain morbidity information from the long-term follow-up data. Secondly, the measurement of BP may not follow the standard. For example, the time, position and device of BP measurement were not recorded and may lack consistency. This is a general practice in clinical practice; however, the impact of limitation was partially eliminated by the fact that individual patients are very likely have been assessed using similar procedures. Thirdly, some lifestyle factors such as smoking habits, alcohol, coffee, and psychological stress were not included in the analysis due to nonuniform data collection in the EMR. Fourthly, only the short-term efficacy has been assessed in this study, since it is difficult to obtain the long-term followup data from the real-world. Finally, the economic data was based on the practical cost generated from the hospitals included in this study, which may lead to some bias. For instance, only the expenses generated in the hospital can be obtained in the analysis. The cost therapies purchased from pharmacy outside of the hospital are difficult to be considered, which may lead to the underestimation of the real cost in the real-world.

\section{Conclusion}

This study focused on the effectiveness and cost of hypertension patients in the real-world clinical practice and utilized the data extracted from EMR. The patients receiving $\mathrm{CRH}$ showed a higher overall BP control rate than the other three anti-hypertensive drugs commonly prescribed, which indicated that Compound Reserpine and Hydrochlorothiazide Tablets have a better benefit in BP control for hypertensive patients. Also, the total cost for hypertension treatment associated with $\mathrm{CRH}$ treatment was lower in comparison with the other three commonly prescribed hypertensive medicines. These findings suggest that Compound Reserpine and Hydrochlorothiazide Tablets could be a better option for hypertensive patients.

\section{Ethics Approval and Informed Consent}

This study used data from patients' electronic medical records (EMR). The patient data confidentiality was guaranteed and all study data were de-identified and fully compliant with the Health Insurance Portability and Accountability Act (HIPAA). Therefore, approval from an institutional review board and written informed consent for their data were not required. This study was carried out in accordance with the principles of the Declaration of Helsinki.

\section{Author Contributions}

SPL and LTL were responsible for study design. SPL, XHL, and LTL were responsible for the statistical components in the analysis, and prepared the first draft of the manuscript. All authors contributed to data analysis, drafting or revising the article, gave final approval of the version to be published, and agree to be accountable for all aspects of the work.

\section{Funding}

This paper was funded by China Resources Double-Crane Pharmaceutical Co. Ltd. The study sponsor did not interfere with the study design, data collection, or writing of this manuscript.

\section{Disclosure}

Shunping Li reports grants from China Resources DoubleCrane Pharmaceutical Co. Ltd, during the conduct of the study. Lanting Li is affiliated to Shanghai Palan DataRx Co., Ltd. The authors report no other conflicts of interest in this work.

\section{References}

1. Forouzanfar MH, Liu P, Roth GA, et al. Global burden of hypertension and systolic blood pressure of at least 110 to $115 \mathrm{~mm} \mathrm{Hg}, 1990-2015$. JAMA. 2017;317:165-182. doi:10.1001/jama.2016.19043

2. Gakidou E, Afshin A, Abajobir AA, et al. Global, regional, and national comparative risk assessment of 84 behavioural, environmental and occupational, and metabolic risks or clusters of risks, 1990-2016: a systematic analysis for the Global Burden of Disease Study 2016. Lancet. 2017;390:1345-1422. doi:10.1016/S0140-6736(17)32366-8

3. Lewington S, Lacey B, Clarke R, et al. The burden of hypertension and associated risk for cardiovascular mortality in China. JAMA Intern Med. 2016;176:524-532. doi:10.1001/jamainternmed.2016.0190

4. Zhou B, Bentham J, Cesare MD, et al. Worldwide trends in blood pressure from 1975 to 2015: a pooled analysis of 1479 populationbased measurement studies with $19 \cdot 1$ million participants. Lancet. 2017;389:37-55. doi:10.1016/S0140-6736(16)31919-5

5. Wang J, Zhang L, Wang F, Liu L, Wang H; China National Survey of Chronic Kidney Disease Working G. Prevalence, awareness, treatment, and control of hypertension in China: results from a national survey. Am J Hypertens. 2014;27:1355-1361. doi:10.1093/ajh/hpu053

6. Fang L, Song J, Ma Z, Zhang L, Jing C, Chen D. Prevalence and characteristics of hypertension in mainland Chinese adults over decades: a systematic review. J Hum Hypertens. 2014;28:649-656. doi: $10.1038 /$ jhh. 2014.5

7. Ke Y, Zhu D, Hong H, et al. Efficacy and safety of a single-pill combination of amlodipine/valsartan in Asian hypertensive patients inadequately controlled with amlodipine monotherapy. Curr Med Res Opin. 2010;26:1705-1713. doi:10.1185/03007995.2010.487391

8. Lu J, Lu Y, Wang X, et al. Prevalence, awareness, treatment, and control of hypertension in China: data from 1.7 million adults in a population-based screening study (China PEACE Million Persons Project). Lancet. 2017;390:2549-2558. doi:10.1016/S0140-6736(17) 32478-9

9. Kintscher U. The burden of hypertension. EuroIntervention. 2013;9 (Suppl R):R12-R15. doi:10.4244/EIJV9SRA3 
10. Wang Y, Peng X, Nie X, et al. Burden of hypertension in China over the past decades: systematic analysis of prevalence, treatment and control of hypertension. Eur J Prev Cardiol. 2016;23:792-800. doi:10.1177/2047487315617105

11. Vasan RS, Beiser A, Seshadri S, et al. Residual lifetime risk for developing hypertension in middle-aged women and men: the Framingham Heart Study. JAMA. 2002;287:1003-1010. doi:10.10 01/jama.287.8.1003

12. Veronesi M, Cicero AF, Prandin MG, et al. A prospective evaluation of persistence on antihypertensive treatment with different antihypertensive drugs in clinical practice. Vasc Health Risk Manag. 2007;3:999-1005.

13. Le C, Zhankun S, Jun D, Keying Z. The economic burden of hypertension in rural south-west China. Trop Med Int Health. 2012;17:1544-1551. doi:10.1111/tmi.2012.17.issue-12

14. Lee JH, Kim SH, Kang $\mathrm{SH}$, et al. Blood pressure control and cardiovascular outcomes: real-world implications of the 2017 ACC/ AHA hypertension guideline. Sci Rep. 2018;8:13155. doi:10.1038/ s41598-018-31549-5

15. Oparil S, Schmieder RE. New approaches in the treatment of hypertension. Circ Res. 2015;116:1074-1095. doi:10.1161/CIRCRES AHA.116.303603

16. Gorostidi M, de la Sierra A. Combination therapies for hypertension why we need to look beyond RAS blockers. Expert Rev Clin Pharmacol. 2018;11:841-853. doi:10.1080/17512433.2018.1509705
17. Revision Committee of Clinical Practice Guidelines for the Management of Hypertention in the Community. Clinical practice guidelines for the management of hypertension in the community. Chin J Health Manage. 2015;9:20.

18. Committee of Expert on Hypertention Management in Community. Clinical practice guidelines for the prevention and management of hypertension in the community. Chin Circul J. 2017;32:8.

19. Comittee of Experts on Rational Drug Use,National Health and Family Planning Commission of the P.R.China. Clinical practice guidelines for hypertension rational drug use. Chin J Front Med Sci. 2017;9:98.

20. Chinese Hypertention Committee of the Chinese Medical Doctors Association. Chinese expert consensus on clinical application of compound reserpine and triamterene tablets. Chin J Hypertens. 2016;24:945.

21. Wang Hongyi SN, Shan J, Yuanyuan C, Luyan W. Efficacy and safety of reserpine and triamterene compound tablets and indapamide inpatients with essential hypertension: a randomized controlled clinical study. Chin J Hypertens. 2016;24:6.

22. Wu YQ, Hu YH, Ren T, et al. Cost-effectiveness analysis on compound anti-hypertensive tablets for primary hypertension. Chin J Epidemiol. 2008;29:4.
ClinicoEconomics and Outcomes Research

\section{Publish your work in this journal}

ClinicoEconomics and Outcomes Research is an international, peerreviewed open-access journal focusing on Health Technology Assessment, Pharmacoeconomics and Outcomes Research in the areas of diagnosis, medical devices, and clinical, surgical and pharmacological intervention. The economic impact of health policy and health systems

\section{Dovepress}

organization also constitute important areas of coverage. The manuscript management system is completely online and includes a very quick and fair peer-review system, which is all easy to use. Visit http://www.dovepress.com/testimonials.php to read real quotes from published authors. 